\title{
Enhancing Photocatalytic Degradation of Methylene Blue Using ZnO/Carbon Dots Nanocomposite Derived From Coffee Grounds
}

\author{
Akhiruddin Maddu*, Reny Meliafatmah, Erus Rustami \\ Department of Physics, Bogor Agricultural University (IPB University), \\ Jl. Meranti, Gedung Wing S, Kampus IPB Dramaga, Bogor 16680, Indonesia
}

Received: 9 December 2019

Accepted: 6 April 2020

\begin{abstract}
In this article, we report the enhancement of the photocatalytic activity of $\mathrm{ZnO} /$ carbon dots (CDs) nanocomposite in degrading methylene blue (MB) dye. Carbon dots (CDs) were synthesized by a hydrothermal method utilizing coffee grounds as a carbon source. $\mathrm{ZnO} / \mathrm{CD}$ s nanocomposite was synthesized by a single-step and in-situ sonochemical process. The particle size of CDs measured by dynamic light scattering (DLS) was found at about $7.7 \mathrm{~nm}$. The result of X-ray diffraction analysis confirmed that the hexagonal wurtzite structure of $\mathrm{ZnO}$ nanoparticle has a small crystal size and the lattice parameters decreasing due to CDs addition. The surface morphology images were taken by scanning electron microscopy (SEM) shows a very fine particle both for pure $\mathrm{ZnO}$ nanoparticle and $\mathrm{ZnO} / \mathrm{CDs}$ nanocomposite. The result of Energy Dispersive X-Ray Spectroscopy (EDXS) analysis confirmed the presence of the carbon element in the $\mathrm{ZnO} / \mathrm{CDs}$ nanocomposite indicated that the nanocomposite has been formed. The result of the photocatalytic test showed that the $\mathrm{ZnO} / \mathrm{CDs}$ nanocomposite photocatalyst had significantly increased photocatalytic activity compared to the pure $\mathrm{ZnO}$ nanoparticle photocatalyst. $\mathrm{ZnO} / \mathrm{CDs}$ nanocomposite photocatalyst resulted in a photodegradation rate three times higher than pure $\mathrm{ZnO}$ nanoparticle photocatalyst and nine times higher than the photolysis treatment (without photocatalyst). Whereas the degradation efficiency of MB using $\mathrm{ZnO} / \mathrm{CDs}$ nanocomposite photocatalyst was twice higher than using pure $\mathrm{ZnO}$ nanoparticles and four times higher than photolysis treatment.
\end{abstract}

Keywords: carbon dots, coffee grounds, nanocomposite, photocatalysis, $\mathrm{ZnO}$ nanoparticle

\section{Introduction}

Fujishima and Honda discovered a water splitting phenomenon in their experiment on the electrochemical

*e-mail: akhiruddin@apps.ipb.ac.id photolysis of water used semiconductor electrode [1]. During their experiment, Fujishima and Honda discovered a photocatalytic activity of $\mathrm{TiO}_{2}$ and began testing this semiconductor as a photocatalyst. Since then the development of the photocatalysis mechanism involving the semiconductor material as a photocatalyst to decompose the organic dyes began to increase very 
rapidly until now. The photocatalysis process takes place through the activation of semiconductor materials by suitable photon energy that generates the active charges (electron-hole pairs) which will induce catalytic reactions at semiconductor surfaces [2-5]. Traditionally, the $\mathrm{TiO}_{2}$ is a metal-oxide-semiconductor that is the earliest and most commonly used as a photocatalyst to decompose organic dyes [4-8].

As a consequence of early Fujishima and Honda's experiment, there are further numerous experiments on the use of semiconductors, such as $\mathrm{ZnO}$, as photocatalysts for the decomposition of some organic pollutants [9-14], but the photocatalytic activity of $\mathrm{ZnO}$ is no better than $\mathrm{TiO}_{2}$. Hence, various attempts have been conducted to enhance the photocatalytic activity of $\mathrm{ZnO}$ by various modifications such as doping or hybridization or compositing with other materials. This modification changes the optical absorption property of photocatalyst while making charges transfer more effective in the photocatalysis mechanism. Some previous studies have modified $\mathrm{ZnO}$ photocatalyst by doping with various elements such as silver [15], magnesium [16], iron [17, 18], carbon [18], and nitrogen [19-21]. Other efforts have making heterostructures or heterojunctions of $\mathrm{ZnO}$ with other semiconductor materials such as $\mathrm{SnO}_{2}$ [22], $\mathrm{ZnS}$ [23], $\mathrm{NiO}$ [24], $\mathrm{CdS}$ [25], and $\mathrm{CdO}$ [26]. In addition, several studies have conducted a hybridization of $\mathrm{ZnO}$ with $\mathrm{g}-\mathrm{C}_{3} \mathrm{~N}_{4}$ to enhance its photocatalytic activity [27-29]. Previous studies have also conducted modification of $\mathrm{ZnO}$ with carbon nanomaterials to form heterostructures including carbon nanotube [30], carbon nanofiber [31], activated carbon fiber [32], and carbon dots [33-36].

Carbon dots (CDs) have been developed as new photocatalyst materials because of their ability to generate charge carriers when is exposed with appropriate photon energy. As a nanomaterial, CDs are known to be able to absorb the wide spectrum of the electromagnetic energy from UV to visible spectrum (blue-green region), so that they can contribute to the photocatalysis mechanism, both alone or in combination with various semiconductor materials [37-40]. CDs have been combined with several semiconductor materials to form nanocomposites or heterostructures, such as with $\mathrm{ZnO}$, to enhance charges transfer in the photocatalyst [33-36].

This study aims to enhance the photocatalytic activity of $\mathrm{ZnO}$ nanoparticles by the addition of $\mathrm{CDs}$ derived from coffee grounds which is the rest of steeping which is thrown away after being drunk by coffee drinkers. This addition is aimed to facilitate the transfer of photon-generated charges (electron-hole pairs) by preventing early recombination in bulk $\mathrm{ZnO}$ photocatalyst. The $\mathrm{CDs}$ addition into $\mathrm{ZnO}$ nanoparticles can accelerate the photocatalytic reaction which in turn would increase photocatalytic activity and enhance the degradation efficiency and degradation rate of the dye. Synthesis of CDs was conducted by a hydrothermal method utilizing coffee grounds as carbon source, then the synthesis of $\mathrm{ZnO} / \mathrm{CDs}$ nanocomposite was carried out in one-step and one-pot process by the sonochemical method.

\section{Materials and Methods}

\section{Synthesis and Characterization of Carbon Dots \\ (CDs)}

To synthesis carbon dots (CDs), $2.5 \mathrm{~g}$ of coffee grounds was poured into $250 \mathrm{~mL}$ of $\mathrm{NaOH}(0.2 \mathrm{M})$ solution while stirred until fully mixed. The mixture was poured into a stainless steel autoclave to be hydrothermally processed at $100^{\circ} \mathrm{C}$ for 1 hour. The dark brown suspension resulted was filtered to separate the precipitate from the supernatant. The supernatant containing carbon nanoparticles (CDs) was diluted with distilled water then optically characterized to determine their optical absorption by using UVVis spectrophotometer (USB4000 Ocean Optics Spectrophotometer). The particle size distribution of CDs was measured by dynamic light scattering (DLS) method using Particle Size Analyzer (PSA, VASCO).

\section{Synthesis and Characterization of Photocatalysts}

Synthesis of pure $\mathrm{ZnO}$ nanoparticle photocatalyst was conducted by dissolving $4 \mathrm{~g}$ of $\mathrm{Zn}\left(\mathrm{CH}_{3} \mathrm{COO}\right)_{2} \cdot 2 \mathrm{H}_{2} \mathrm{O}$ $(0.25 \mathrm{M})$ in $100 \mathrm{~mL} \mathrm{NaOH}(0.2 \mathrm{M})$ solution. The mixed solution was transferred into the beaker glass $(150 \mathrm{~mL})$ then placed into the ultrasonic bath which has been filled with enough water. Ultrasonic bath is turned on for 2 hours for sonochemical processing. The resulting precipitate was filtered and then dried on the hotplate at $100{ }^{\circ} \mathrm{C}$ for 2 hours. The dry precipitate powder was annealed in the furnace at $300^{\circ} \mathrm{C}$ for 5 hours to obtain pure $\mathrm{ZnO}$ nanoparticle powder.

Synthesis of $\mathrm{ZnO} / \mathrm{CDs}$ nanocomposite photocatalyst was conducted by in-situ sonochemical method in onestep and one-pot using an ultrasonic bath. As much as $4 \mathrm{~g}$ of $\mathrm{Zn}\left(\mathrm{CH}_{3} \mathrm{COO}\right)_{2} \cdot 2 \mathrm{H}_{2} \mathrm{O}$ was dissolved in 100 $\mathrm{mL}$ of CDs solution that has been derived from coffee grounds. The $\mathrm{pH} 12$ of the mixed solution was adjusted by gradually dropping of $\mathrm{NaOH}(8 \mathrm{M})$ solution while stirred. Then the mixed solution was transferred into the beaker glass $(150 \mathrm{~mL})$ then placed in the ultrasonic bath which has been filled with enough water. Ultrasonic bath is turned on for 2 hours for sonochemical processing. The resulting suspension was centrifuged at $3000 \mathrm{rpm}$ for $30 \mathrm{~min}$ to obtain a brown precipitate. The resulting precipitate was filtered and washed by distilled water three times alternately to remove impurities then dried on the hotplate at $100^{\circ} \mathrm{C}$ for 2 hours. The dry brown powder was annealed in the furnace at $300^{\circ} \mathrm{C}$ for 5 hours to obtain brown $\mathrm{ZnO} / \mathrm{CDs}$ nanocomposite.

Both pure $\mathrm{ZnO}$ nanoparticle and $\mathrm{ZnO} / \mathrm{CDs}$ nanocomposite were characterized by using $\mathrm{X}$-ray diffraction (XRD) to determine their crystal parameters 
including crystal phase, crystal lattices, and crystallite size. Morphology of the products was investigated by using scanning electron microscopy (SEM) and chemical composition was determined by using Energy Dispersive X-ray Spectroscopy (EDXS) analysis taken simultaneously with SEM images capturing.

\section{Photodegradation Testing of Methylene Blue}

Photodegradation treatments of metylene blue (MB) dye were conducted, namely UV photolysis, photocatalysis treatment using pure $\mathrm{ZnO}$ nanoparticle, and photocatalysis treatment using $\mathrm{ZnO} / \mathrm{CDs}$ nanocomposite as photocatalyst. Photocatalysis treatment was conducted by directly exposing the UV light to the MB dye solution without photocatalyst. Photocatalysis treatments was carried out in a cuvette under UV light irradiation using a 6W UVB lamp $(360 \mathrm{~nm})$. As much as $4 \mathrm{~mL}$ of $\mathrm{MB}$ dye solution with an initial concentration of $5 \mathrm{ppm}$ was poured into the cuvette. Then, $1 \mathrm{mg}$ of each photocatalyst (pure $\mathrm{ZnO}$ nanoparticle and $\mathrm{ZnO} / \mathrm{CDs}$ nanocomposite) was dispersed into the MB solution. Before irradiation, the solution was stirred to achieve the adsorptiondesorption equilibrium between MB dye and photocatalysts. Furthermore, the dye-photocatalyst suspension was irradiated by UV light at room temperature for 150 minutes. Every 30 minutes of irradiation, the cuvette is inserted into the cuvette holder of UV-Vis spectrophotometer (USB4000 Ocean Optics Spectrophotometer) to be measured the absorption spectra of the MB solution after irradiation. The absorbance spectra were used to determine the concentration of MB solution after every 30 minutes of irradiation for each solution. The concentration of MB solution is determined based on the absorbance change at the specific absorption wavelength of the $\mathrm{MB}$ solution. By using a standard curve of $\mathrm{MB}$, the quantitative concentration of $\mathrm{MB}$ can be determined for each photodegradation treatment. Photodegradation efficiency $(\eta)$ is calculated based on the absorbance of MB dye at the specific absorption wavelength by the equation as follows:

$$
\eta(\%)=\left(A_{o}-A_{t}\right) / A_{o} \times 100 \%
$$

...where $A_{o}$ is the initial absorption of the dye, and $A_{t}$ is the absorption of the dye at a given UV irradiation time.

To determine the photodegradation rate (rate constant) of $\mathrm{MB}$ dye, we have to make a linear curve between $\mathrm{Ln}\left(\mathrm{C} / \mathrm{C}_{\mathrm{o}}\right)$ and irradiation time ( $\left.\mathrm{t}\right)$ according to equation (2), namely the natural logarithmic relationship between the concentration of MB and the irradiation time $(\mathrm{t})$ as relation below [35]

$$
\ln \left(\mathrm{C} / \mathrm{C}_{\mathrm{o}}\right)=-k t
$$

...where $\mathrm{C}_{\mathrm{o}}$ is the concentration of $\mathrm{MB}$ solution at $\mathrm{t}=0$, i.e the concentration before treatment, $\mathrm{C}$ is the

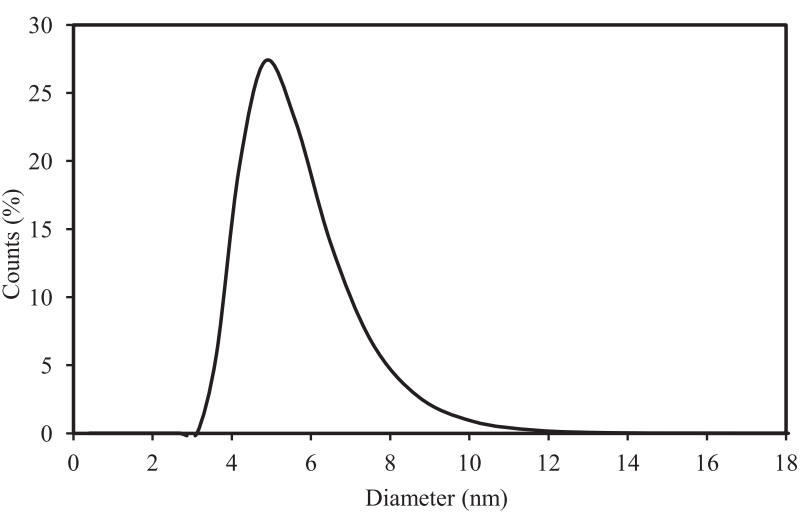

Fig. 1. The particle size distribution of carbon dots (CDs).

concentration of MB every treatment time $\mathrm{t}$ (second), and $k$ is a rate constant of MB degradation.

\section{Results and Discussion}

\section{Characteristics of Carbon Dots (CDs)}

The particle size distribution of CDs was measured by using particle size analyzer (PSA) based on dynamic light scattering (DLS). Fig. 1 shows the particle size distribution of CDs derived from coffee grounds. The resulting curve is wide enough indicating that the particle size of CDs varies greatly, from around 3 to $10 \mathrm{~nm}$, with a predominance of particle size at around $7.74 \mathrm{~nm}$. These results indicate that the carbon nanoparticle that has been derived from coffee grounds by hydrothermal method has nanostructure with a very small size so that it can be stated as quantum dots. Fig. 2 shows the absorption spectrum of the CDs solution covering quite broad of the electromagnetic spectrum from UV $(\sim 350 \mathrm{~nm})$ to the visible $(\sim 600 \mathrm{~nm})$ range with an absorption peak at around $410 \mathrm{~nm}$ (violet). Based on this characteristic, CDs can be involved in photocatalysis mechanisms because of the ability to absorb UV-visible energy of electromagnetic spectrum

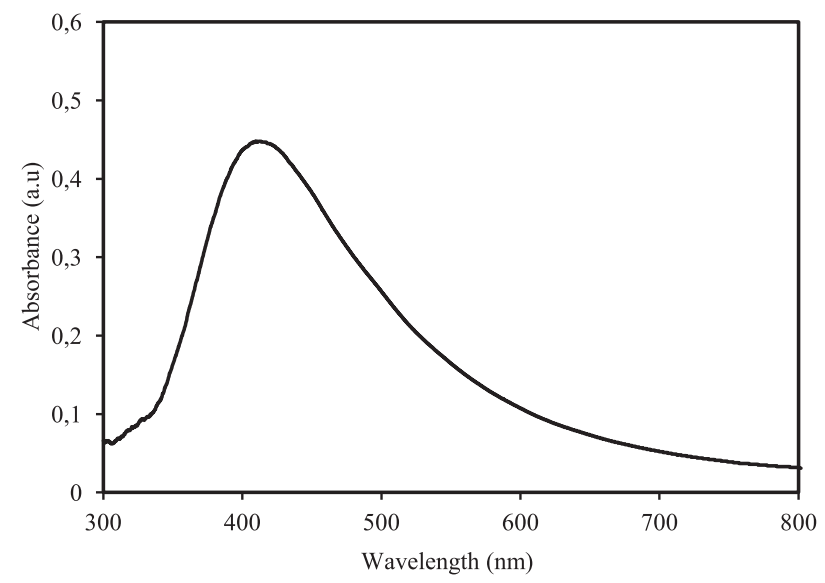

Fig. 2. Absorption spectra of carbon dots (CDs). 
which can generate more electron-holes pairs to induce photocatalysis reaction, as a result, can improve the photocatalytic activity of $\mathrm{CDs} / \mathrm{ZnO}$ heterostructure [33-36].

\section{Crystal Parameters of Photocatalysts}

Both pure $\mathrm{ZnO}$ nanoparticle and $\mathrm{ZnO} / \mathrm{CDs}$ nanocomposite were characterized by using X-ray diffraction to investigate their crystal phase, crystal lattice, and crystallite size. Fig. 3 shows a diffraction pattern of both samples. There is no significant difference in both diffraction patterns where the diffraction peaks were identified as belonging to $\mathrm{ZnO}$. There is no carbon phase (C) present in a diffraction pattern for both samples, including in $\mathrm{ZnO} / \mathrm{CDs}$ nanocomposite sample. This is because the fraction of $\mathrm{CDs}$ in the $\mathrm{ZnO} / \mathrm{CDs}$ nanocomposite sample is relatively small when compared to the fraction of $\mathrm{ZnO}$ nanoparticle.

Diffraction pattern of pure $\mathrm{ZnO}$ nanoparticle, as in Fig. 3a), shows the $\mathrm{ZnO}$ diffraction peaks respectively present at $2 \theta=31.76^{\circ}, 34.41^{\circ}, 36.24^{\circ}, 47.53^{\circ}, 56.59^{\circ}$, $62.82^{\circ}, 67.92^{\circ}$ which corresponding to the lattice planes (hkl) of (100), (002), (101), (102), (110), (103), and (112). All the peaks present after annealing the precursor at $300^{\circ} \mathrm{C}$ are assigned as hexagonal wurtzite structure of $\mathrm{ZnO}$ (JCPDS card No. 36-1451) [15-21]. While, the diffraction pattern for $\mathrm{ZnO} / \mathrm{CDs}$ nanocomposite, as in Fig. 3b), almost no difference when compared to the diffraction pattern of pure $\mathrm{ZnO}$ nanoparticle sample. Therefore, the addition of CDs into $\mathrm{ZnO}$ nanoparticles almost not change the crystal phase of $\mathrm{ZnO}$.

The crystal phase of $\mathrm{ZnO}$ nanoparticle can be confirmed based on its lattice parameters. The lattice parameter values were calculated using the Cohen method based on the diffraction pattern of sample. The calculation results show that the lattice parameter values obtained correspond to the hexagonal wurtzite structure of ZnO (JCPDS card No. 36-1451) [15-21]. The results of the lattice parameter calculation are presented in Table 1. Data obtained show a small

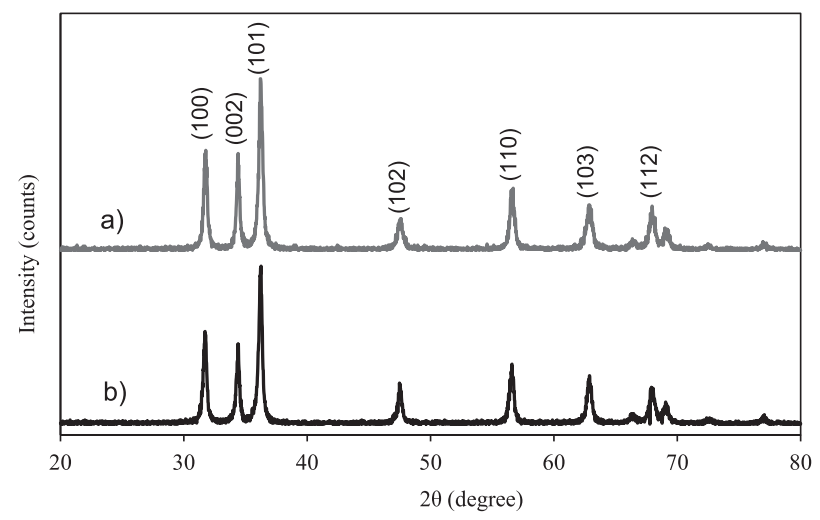

Fig. 3. XRD pattern of a) pure $\mathrm{ZnO}$ nanoparticle and b) $\mathrm{ZnO} / \mathrm{CDs}$ nanocomposite.
Table 1. Lattice parameters of pure $\mathrm{ZnO}$ nanoparticle and $\mathrm{ZnO}$ / CDs nanocomposite.

\begin{tabular}{|c|c|c|c|c|}
\hline \multirow{2}{*}{ Sample } & \multicolumn{2}{|c|}{ Lattice parameters $[\AA]$} & \multicolumn{2}{c|}{ Accuracy [\%] } \\
\cline { 2 - 5 } & $\mathrm{a}$ & $\mathrm{c}$ & $\mathrm{a}$ & $\mathrm{c}$ \\
\hline $\mathrm{ZnO}$ & 3.2503 & 5.2089 & 99.96 & 99.93 \\
\hline $\mathrm{ZnO} / \mathrm{CDs}$ & 3.2463 & 5.1986 & 99.91 & 99.88 \\
\hline
\end{tabular}

variation in the lattice spacing of $\mathrm{ZnO}$ nanoparticle due to $\mathrm{CDs}$ addition. The lattice spacing for the pure $\mathrm{ZnO}$ nanoparticle is $\mathrm{a}=\mathrm{b}=3.2503 \AA$ and $\mathrm{c}=5.2089 \AA$. While for $\mathrm{ZnO} / \mathrm{CD}$ s nanocomposite, the lattice spacing is $\mathrm{a}=\mathrm{b}=3.2463 \AA \mathrm{c}=5.1986 \AA$, there is a slightly decreased when compared to pure $\mathrm{ZnO}$ nanoparticle. Decreasing the value of lattice spacing due to carbon insertion into the lattice structure of $\mathrm{ZnO}$ nanoparticle. The accuracy of the calculating results of lattice parameters is smaller for $\mathrm{ZnO} / \mathrm{CD}$ nanocomposite than pure $\mathrm{ZnO}$ nanoparticle (Table 1), this is because of the decrease in lattice spacing due to the addition of CDs.

The average crystallite size (ACS) of the samples was calculated based on full width at half maximum (FWHM) of diffraction pattern using the DebyeScherrer equation (3) as follows:

$$
\mathrm{D}=\mathrm{k} \lambda / \beta \cos \theta
$$

...where $\mathrm{D}$ is the crystal size, $\mathrm{k}$ is Scherrer constant (0.89), $\lambda$ is X-ray wavelength $(0.154 \mathrm{~nm}), \beta$ is the peak full width at half maximum (FWHM), and $\theta$ is the Bragg diffraction angle.

Fig. 3 shows a considerable peak widening in the diffraction pattern of $\mathrm{ZnO}$ nanoparticle indicating the FWHM value is relatively large. Data presented in Table 2 shows the FWHM of pure $\mathrm{ZnO}$ nanoparticle slightly larger than $\mathrm{ZnO} / \mathrm{CDs}$ nanocomposite that indicating that the average crystallite size of pure $\mathrm{ZnO}$ nanoparticle smaller than $\mathrm{ZnO} / \mathrm{CDs}$ nanocomposite. The calculation results of the ACS of both samples are presented in Table 2. It shows that the addition of CDs greatly affected the ACS of $\mathrm{ZnO} / \mathrm{CDs}$ nanocomposite. The ACS of $\mathrm{ZnO} / \mathrm{CD}$ nanocomposite larger than pure $\mathrm{ZnO}$ nanoparticle. These results demonstrate that CDs were successfully incorporated into $\mathrm{ZnO}$ lattice. The addition of $\mathrm{CDs}$ resulted in extending the distance between the atoms in the crystal lattice of $\mathrm{ZnO}$ so that the crystallite size increased.

Table 2. The average crystallite size (ACS) of pure $\mathrm{ZnO}$ nanoparticle and $\mathrm{ZnO} / \mathrm{CDs}$ nanocomposite.

\begin{tabular}{|c|c|c|}
\hline Sample & FWHM (101) & $\begin{array}{c}\text { The average crystallite size } \\
{[\mathrm{nm}]}\end{array}$ \\
\hline $\mathrm{ZnO}$ & 0.344 & 30.622 \\
\hline $\mathrm{ZnO} / \mathrm{CDs}$ & 0.307 & 34.694 \\
\hline
\end{tabular}



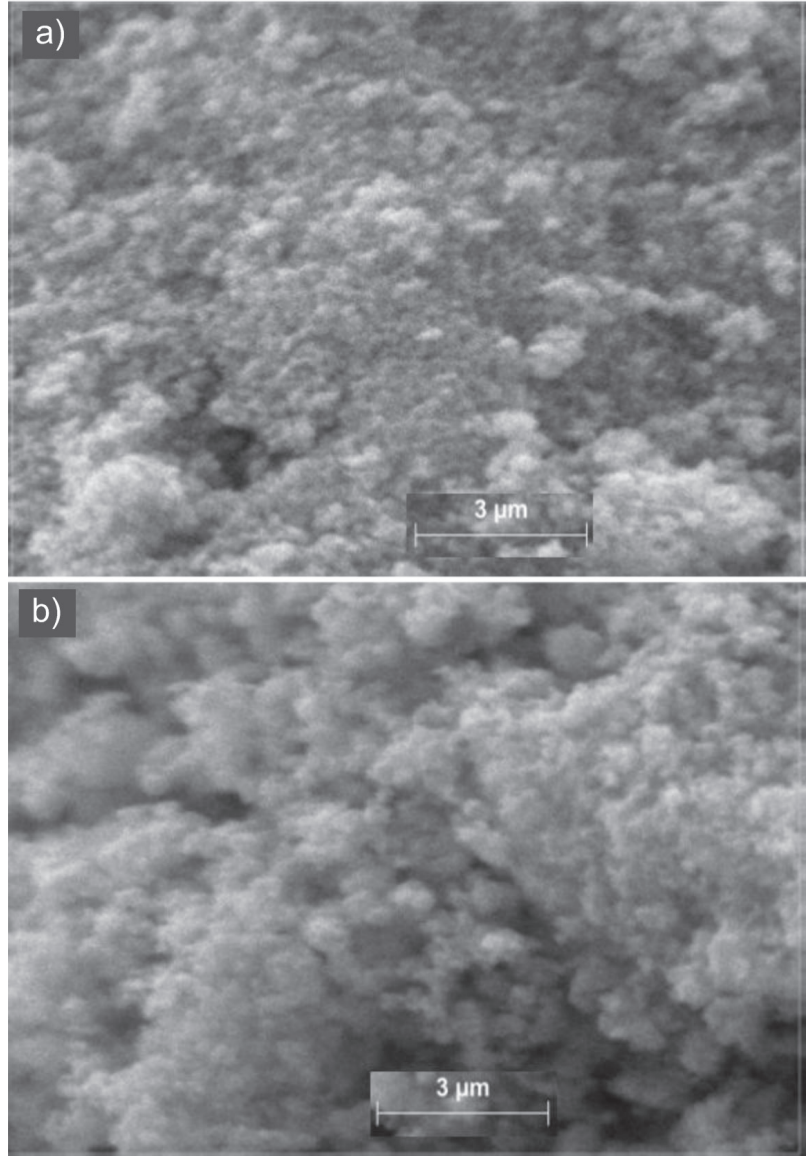

Fig. 4. SEM images of a) pure $\mathrm{ZnO}$ nanoparticle and b) $\mathrm{ZnO} /$ CDs nanocomposite.

\section{Morphology and Chemical Composition of Photocatalysts}

Surface morphology images of both photocatalyst samples were taken by using scanning electron microscopy (SEM). Fig. 4 shows morphology images of the pure $\mathrm{ZnO}$ nanoparticle and $\mathrm{ZnO} / \mathrm{CDs}$ nanocomposite with a magnification of 10,000 times. Both images show a homogeneous surface morphology with very fine granules. Morphology of pure $\mathrm{ZnO}$ nanoparticle appeared finer than $\mathrm{ZnO} / \mathrm{CDs}$ nanocomposite which appeared to clot. It was seen that the size of the granules for the pure $\mathrm{ZnO}$ nanoparticle was smaller than the $\mathrm{ZnO} / \mathrm{CDs}$ nanocomposite. This is because, in the $\mathrm{ZnO} / \mathrm{CDs}$ nanocomposite, $\mathrm{ZnO}$ particles are covered by $\mathrm{CDs}$, so slightly increasing the size of the $\mathrm{ZnO}$ particles.
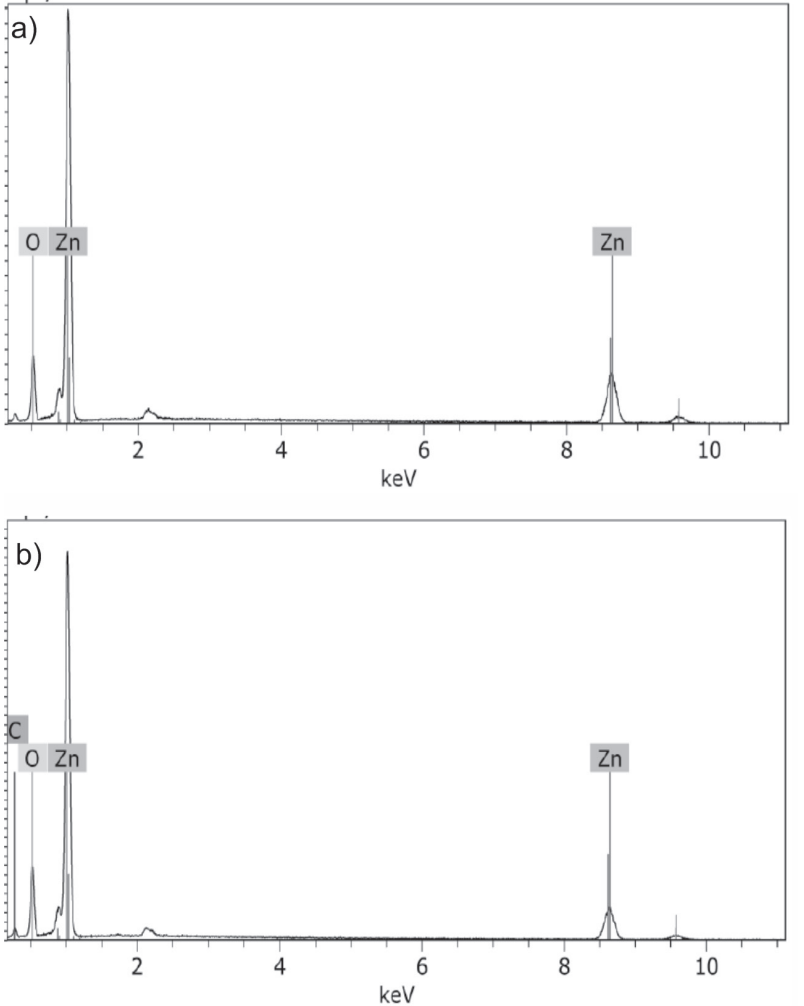

Fig. 5. EDXS spectra of a) pure $\mathrm{ZnO}$ nanoparticle and b) $\mathrm{ZnO} /$ CDs nanocomposite.

The chemical composition of the photocatalyst materials was identified based on data from EnergyDispersive X-ray spectroscopy (EDXS). Fig. 5 shows the EDXS spectra for both pure $\mathrm{ZnO}$ nanoparticle and $\mathrm{ZnO} / \mathrm{CDs}$ nanocomposite. Peaks of zinc and oxygen elements present in the spectra where the peak of zinc dominating the spectra. Spectra of $\mathrm{ZnO} / \mathrm{CDs}$ nanocomposite shows a peak of carbon indicating the presence of carbon elements originating from $\mathrm{CDs}$ in the nanocomposite. Table 3 presents the elemental composition of both photocatalyst materials. The percentage ratio of $\mathrm{Zn}$ and $\mathrm{O}$ for the pure $\mathrm{ZnO}$ nanoparticle is more than 1 , which is 1.32 , indicating that in the sample, not all $\mathrm{Zn}$ atoms bond to the $\mathrm{O}$ atom but there are several $\mathrm{Zn}$ atoms stand-alone. The sample of $\mathrm{ZnO} / \mathrm{CDs}$ nanocomposite has the percentage ratio of $\mathrm{Zn}$ and $\mathrm{O}$ is 0.77 and is worth 1.29 for the percentage ratio of $\mathrm{Zn}$ and $\mathrm{C}$, this indicates that $\mathrm{Zn}$ atoms are more bound to $\mathrm{C}$ than $\mathrm{O}$ formed at $\mathrm{CDs}$.

Table 3. EDXS analysis of pure $\mathrm{ZnO}$ nanoparticles and $\mathrm{ZnO} / \mathrm{CDs}$ nanocomposite.

\begin{tabular}{|c|c|c|c|c|c|}
\hline \multirow{2}{*}{ Sample } & \multicolumn{3}{|c|}{ Element } & \multicolumn{2}{c|}{ Ratio } \\
\cline { 2 - 6 } & $\mathrm{C}($ at. \%) & O (at. \%) & Zn (at. \%) & Zn/O & Zn/C \\
\hline $\mathrm{ZnO}$ & - & 43.18 & 56.82 & 1.32 & - \\
\hline $\mathrm{ZnO} / \mathrm{CDs}$ & 24.92 & 42.52 & 32.57 & 0.77 & 1.29 \\
\hline
\end{tabular}




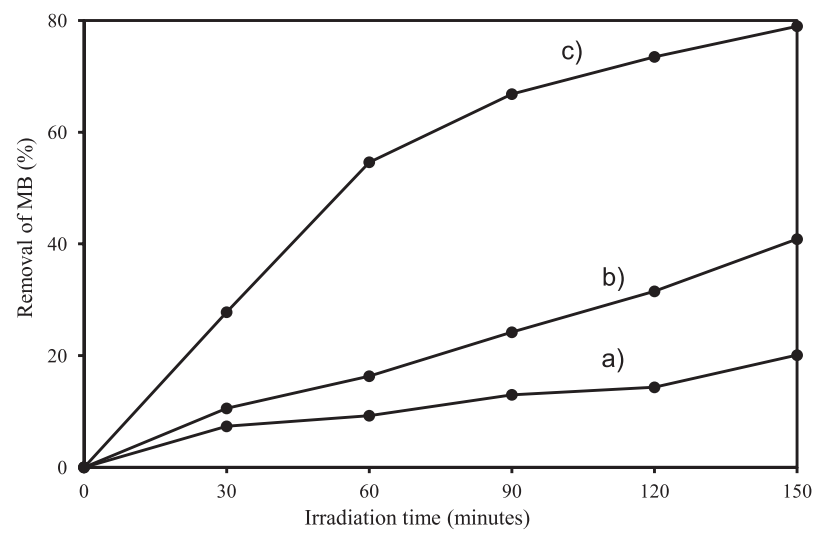

Fig. 6. Removal percentage of $\mathrm{MB}$ dye: a) photolysis, b) photocatalysis using pure $\mathrm{ZnO}$ nanoparticle, and c) photocatalysis using $\mathrm{ZnO} / \mathrm{CDs}$ nanocomposite.

\section{Photocatalytic Activity of Photocatalysts}

Three different photodegradation treatments of MB dye were conducted, namely UV photolysis (without photocatalyst), photocatalysis with pure $\mathrm{ZnO}$ nanoparticle, and photocatalysis with $\mathrm{ZnO} /$ CDs nanocomposite. Photodegradation treatments were conducted using a $6 \mathrm{~W}$ UVB $(360 \mathrm{~nm})$ lamp as a light source. As a control treatment, photolysis was conducted by directly exposing the UV source to MB solution without photocatalyst contains. Photocatalytic degradation of $\mathrm{MB}$ dye was conducted by exposing the UV light to the MB-photocatalyst suspension for both photocatalysts used, which is pure $\mathrm{ZnO}$ nanoparticle and $\mathrm{ZnO} / \mathrm{CDs}$ nanocomposite. UV Lamp used as light source because the $\mathrm{ZnO}$ photocatalyst has strong absorption in the UV spectrum and CDs also has UV absorption.
Fig. 6 shows the percentage of dye removal over time for the three photodegradation treatments for 150 minutes. Photolysis treatment did not result in a significant decrease of MB dye, it only able to degrade $20 \%$ of $\mathrm{MB}$ compounds during 150 minutes of UV irradiation, this is because the UV energy is not able to break quickly and optimally chemical bonds in the MB compound. The photocatalysis treatment was significant in removing $\mathrm{MB}$ dye in solution, especially those using $\mathrm{ZnO} / \mathrm{CDs}$ nanocomposite photocatalyst. The use of pure $\mathrm{ZnO}$ nanoparticle was only able to reduce $40 \%$ of $\mathrm{MB}$ content in solution while the use of $\mathrm{ZnO} / \mathrm{CDs}$ nanocomposite photocatalyst was able to reduce nearly $80 \%$ of MB content during 150 minutes of photocatalysis treatment. Therefore, the degradation of $\mathrm{MB}$ dye for photocatalytic treatment using $\mathrm{ZnO} / \mathrm{CDs}$ nanocomposite as photocatalyst much faster than using pure $\mathrm{ZnO}$ nanoparticle.

Fig. 7 shows the curves of the $\mathrm{Ln}(\mathrm{C} / \mathrm{Co})$ versus time (t) for the three different photodegradation treatments. The slope of the curve represents the photodegradation rate (rate constant) of the MB dye, the higher the slope of the photodegradation curve the higher the photodegradation rate. The photocatalytic treatment using $\mathrm{ZnO} / \mathrm{CDs}$ nanocomposite photocatalyst shows a very large slope when compared to the curves for photocatalytic treatment using pure $\mathrm{ZnO}$ nanoparticle as well as by photolysis treatment. The rate constants of the photodegradation treatments are shown in Table 4 , it is found that photocatalysis treatment using $\mathrm{ZnO} / \mathrm{CDs}$ nanocomposite as photocatalyst three times more effective than photocatalysis treatment using pure $\mathrm{ZnO}$ nanoparticle, even almost eight times more effective than photolysis treatment (directly irradiation by UV lamp). The addition of CDs greatly contributed to the increase in the photocatalytic activity

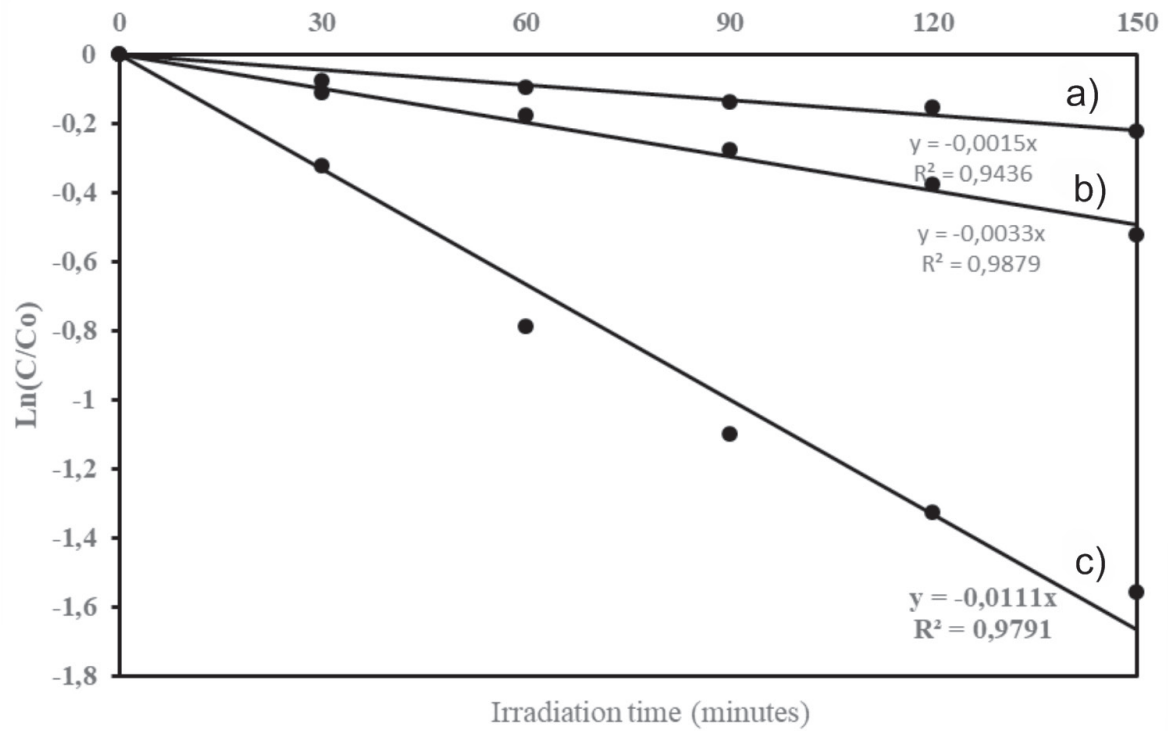

Fig. 7. Degradation rates of $\mathrm{MB}$ dye: a) photolysis, b) photocatalysis using pure $\mathrm{ZnO}$ nanoparticle, and c) photocatalysis using $\mathrm{ZnO} / \mathrm{CDs}$ nanocomposite 
Table 4. The photodegradation parameters of the MB dye by different treatments.

\begin{tabular}{|c|c|c|}
\hline Treatment & $\begin{array}{c}\text { Photodegradation } \\
\text { rate }\left[\mathrm{min}^{-1}\right]\end{array}$ & $\begin{array}{c}\text { Photodegradation } \\
\text { efficiency [\%] }\end{array}$ \\
\hline Photolysis & 0.0015 & 20.97 \\
\hline $\begin{array}{c}\text { Photocatalysis } \\
\text { with ZnO }\end{array}$ & 0.0033 & 41.54 \\
\hline $\begin{array}{c}\text { Photocatalysis } \\
\text { with ZnO/CDs }\end{array}$ & 0.0111 & 80.34 \\
\hline
\end{tabular}

of $\mathrm{ZnO} / \mathrm{CDs}$ nanocomposite in degrading $\mathrm{MB}$ dye compound.

The degradation efficiency of three photodegradation treatments is presented in Table 4. It is found that the photodegradation efficiency for photocatalysis treatment using $\mathrm{ZnO} / \mathrm{CDs}$ nanocomposite is almost twice higher than using pure $\mathrm{ZnO}$ nanoparticles, and four times higher than photolysis treatment. Photocatalytic degradation using $\mathrm{ZnO} / \mathrm{CDs}$ nanocomposite able to degrade the MB content in solution up to $80 \%$ for 150 minutes irradiation by UV light. The obtained result in this study is comparable to those resulted by $\mathrm{Yu}$ et al which using $\mathrm{ZnO} / \mathrm{CDs}$ nanocomposites as photocatalysts, which are able to degrade $80 \%$ of benzene [36]. However, there was a difference, Yu et al achieved $80 \%$ degradation after photocatalysis treatment for 4 hours whereas in this study only about 150 minutes irradiation by UV light. Yu et al used three $8 \mathrm{~W}$ visible light lamps to irradiate the photocatalyst. This result also comparable with the result obtained by Bozetine et al which also using $\mathrm{ZnO}-\mathrm{CDs}$ nanocomposite as a photocatalyst to degrade the rhodamine B dye [35]. However, Bozetine et al. found a photodegradation rate higher than this study an also faster to achieve $90 \%$ degradation of $\mathrm{RhB}$. Bozetine used visible light to irradiate the photocatalyst.

Enhanced photocatalytic activity of $\mathrm{ZnO} / \mathrm{CDs}$ nanocomposite is due to the charges (electronhole pairs) transfer mechanism at the photocatalyst surface more effective. The heterojunction formed in
$\mathrm{ZnO} / \mathrm{CDs}$ nanocomposite increases the separation of photogenerated electron-hole pairs so that the transfer mechanism of the electron-hole pairs becomes more effective which in turn enhanced the photocatalytic activity of the photocatalyst. Rapid separation of electron-hole pairs avoids early recombination in the bulk of photocatalyst. It is known that one of the constraints that result in a low photocatalytic activity is the early recombination mechanism in the bulk of the photocatalyst. Therefore, modifications are needed to facilitate the transfer of active charges to the photocatalyst surface before early recombination occurs within the bulk of $\mathrm{ZnO}$. The obtained result confirmed that the $\mathrm{ZnO} / \mathrm{CDs}$ heterostructure successfully facilitated the transfer process of electron-hole pairs between the $\mathrm{ZnO}$ and $\mathrm{CDs}$ which induce the photocatalytic reaction at the surface of the photocatalyst to enhance the degradation of the MB dye.

Fig. 8 illustrates the energy diagram of the heterostructure of $\mathrm{ZnO} / \mathrm{CDs}$ nanocomposite. The position of the lowest unoccupied molecular orbital (LUMO) and the highest occupied molecular orbital (HOMO) of both materials determines the transfer mechanism of active charges (electron-hole pairs) that photogenerated, as well as affect the reactions that occur on the surface of the photocatalyst. The position of the LUMO and HOMO energy levels of CDs are $-3.99 \mathrm{eV}$ and $-7.04 \mathrm{eV}$ [41], while the conduction band $(\mathrm{CB})$ and valence band (VB) of $\mathrm{ZnO}$ are $-4.05 \mathrm{eV}$ and $-7.25 \mathrm{~V}$ [42]. Therefore, the HOMO energy level of CDs higher than the conduction band of $\mathrm{ZnO}$, likewise, the HOMO energy level of CDs is also higher than the valence band of $\mathrm{ZnO}[33,42]$. Electrons photogenerated in the LUMO of CDs are rapidly injected into the conduction band of $\mathrm{ZnO}$, while holes generated in the valence band of $\mathrm{ZnO}$ are easily injected into the HOMO energy level of CDs. These two active charges together increase the photocatalytic reaction on the surface of photocatalysts.

Oxidative reactions occur simultaneously at both the LUMO of CDs and conduction band (CB) of $\mathrm{ZnO}$, as well as the reductive reactions also occur simultaneously at the HOMO of CDs and valence band

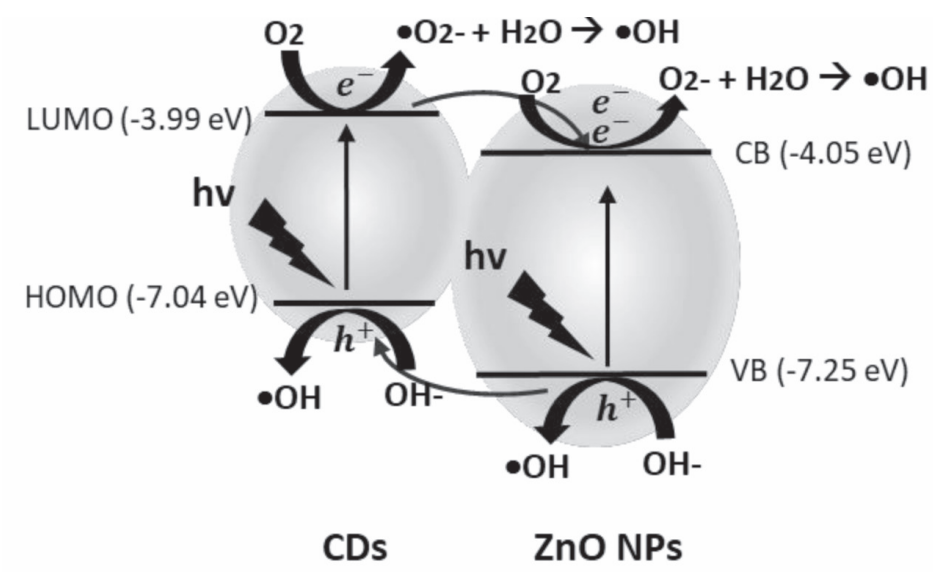

Fig. 8. Photocatalysis mechanism scheme of $\mathrm{ZnO} / \mathrm{CDs}$ nanocomposite. 
(VB) of $\mathrm{ZnO}$. Both oxidative and reductive reactions generate free radicals (e.g. hydroxyl radicals: $\bullet \mathrm{OH}$ ) that very oxidative in nature and able to undergo secondary reactions that can decompose organic compounds like dyes. The simultaneous oxidative and reductive reactions on the photocatalyst surface will increase the formation of free radicals $(\bullet \mathrm{OH})$ thus enhancing the photocatalytic activity of the $\mathrm{ZnO} / \mathrm{CDs}$ nanocomposite system.

On the other hand, the photogeneration of the electron-hole pairs depends on the bandgap energy of materials. The bandgap energy of $\mathrm{ZnO}$ is $3.20 \mathrm{eV}$ [33, 42], while the bandgap energy of CDs is $3.05 \mathrm{eV}$ [41]. Therefore, CDs tend to absorb from the UVB to the blue region while $\mathrm{ZnO}$ fully absorbs the $\mathrm{UV}$ region of the electromagnetic spectrum. The combination of $\mathrm{ZnO}$ and $\mathrm{CDs}$ widen the absorption spectrum of the nanocomposite thereby increasing the number of active charges (electron-hole pairs) that can be generated by light photon (photogeneration). Photogeneration of active charges occurs simultaneously in both materials through exposure to UV light used. The amount of charge which is photogenerated influence the probability of a photocatalytic reaction occurring on the surface of the photocatalysts.

\section{Conclusions}

CDs have been successfully synthesized from coffee grounds by hydrothermal method with an average particle size of $7.74 \mathrm{~nm}$. The combination of CDs and $\mathrm{ZnO}$ nanoparticles that forming a nanocomposite system barely changes the crystal phase but increased the average crystal size of the $\mathrm{ZnO}$ nanoparticles, also significantly changes the morphology of $\mathrm{ZnO}$ nanoparticles. The combination of $\mathrm{CDs}$ and $\mathrm{ZnO}$ nanoparticles form a heterostructure to facilitate the transfer mechanism of photogenerated electrons-holes pairs that induce oxidative-reductive reactions at the surface of photocatalysts. The photocatalytic activity of $\mathrm{ZnO} / \mathrm{CDs}$ nanocomposite significantly increased in degrading $\mathrm{MB}$ dye. The photodegradation rate of MB dye increased almost three times when utilizing $\mathrm{ZnO} / \mathrm{CDs}$ nanocomposite photocatalyst compared to pure $\mathrm{ZnO}$ nanoparticle as a photocatalyst, even almost nine times higher than photolysis treatment. The enhanced photocatalytic activity of $\mathrm{ZnO} / \mathrm{CDs}$ nanocomposite due to the transfer mechanism of electron-hole pairs more effective and efficient in accelerating free radicals production (e.g. hydroxyl radicals) on the surface of the photocatalysts.

\section{Acknowledgements}

This study was fully supported by the Department of Physics, Bogor Agricultural University, Bogor, Indonesia. The authors thank the Department of Physics for any support, especially for using any facilities in completing this study.

\section{Conflict of Interest}

The authors declare no conflict of interest.

\section{References}

1. FUJISHIMA A., HONDA K. Electrochemical Photolysis of Water at a Semiconductor Electrode. Nature, 238, 37, 1972.

2. NAKATA A., FUJISHIMA A. $\mathrm{TiO}_{2}$ photocatalysis: Design and applications. Journal of Photochemistry and Photobiology C: Photochemistry Reviews, 13, 169, 2012.

3. SCHNEIDER J., MATSUOKA M., TAKEUCHI M., ZHANG J., HORIUCHI Y., ANPO M., BAHNEMANN D.W. Understanding $\mathrm{TiO}_{2}$ Photocatalysis: Mechanisms and Materials. Chemical Review, 114, 9919, 2014.

4. NAKATA K., OCHIAI T., MURAKAMI T., FUJISHIMA A., Photoenergy conversion with $\mathrm{TiO}_{2}$ photocatalysis: New materials and recent applications. Electrochimica Acta, 84, 103, 2012

5. YUANGPHO N., TRINH D.T.T., CHANNEI D., KHANITCHAIDECHA W., NAKARUK A. The influence of experimental conditions on photocatalytic degradation of methylene blue using titanium dioxide particle. Journal of the Australian Ceramic Society, 54, 557,2018

6. MADDU A., DENI I., SOFIAN I. Effect of $\mathrm{Cu}$ doping on structural properties and photocatalytic activity of $\mathrm{TiO}_{2}$ nanoparticles synthesized by sol-gel method. Journal of Ceramic Processing Research, 19 (1), 25, 2018.

7. WU W., ZHANG L., ZHAI X., LIANG C., YU K. Preparation and photocatalytic activity analysis of nanometer $\mathrm{TiO}_{2}$ modified by surfactant. Nanomaterials and Nanotechnology, 8, 1, 2018.

8. SHAHREZAEI M., HABIBZADEH S., BABALUO A.A., HOSSEINKHANI H., HAGHIGHI M., HASANZADEH A., TAHMASEBPOUR R. Study of synthesis parameters and photocatalytic activity of $\mathrm{TiO}_{2}$ nanostructures. Journal of Experimental Nanoscience, 12 (1), 45, 2017.

9. KUMAR S.G., RAO K.S.R.K. Zinc oxide based photocatalysis: tailoring surfacebulk structure and related interfacial charge carrier dynamics for better environmental applications. RSC Advances, 5, 3306, 2015.

10. DI MAURO A., FRAGALA M.E., PRIVITERA V., IMPELLIZZERI G. ZnO for application in photocatalysis: From thin films to nanostructures. Materials Science in Semiconductor Processing, 69, 44, 2017.

11. LEE K.M., LAI C.W., NGAI K.S., JUAN J.C. Recent developments of zinc oxide based photocatalyst in water treatment technology: A review. Water Research, 88, 428, 2016.

12. ONG C.B., NG L.Y., MOHAMMAD A.W. A review of $\mathrm{ZnO}$ nanoparticles as solar photocatalysts: Synthesis, mechanisms and applications. Renewable and Sustainable Energy Reviews, 81, 536, 2018.

13. SAMADI M., ZIRAK M., NASERI A., KHORASHADIZADE E., MOSHFEGH A.Z. Recent progress on doped $\mathrm{ZnO}$ nanostructures for visible-light photocatalysis. Thin Solid Films, 605, 1, 2016. 
14. MOHAMMAD MEHDI BANESHI, SAEEDEH JAHANBIN, ALI MOUSAVIZADEH, SEYED ABDOLMOHAMMAD SADAT, ALIREZA RAYEGANSHIRAZI, HAMED BIGLARI Gentamicin Removal by Photocatalytic Process from Aqueous Solution. Polish Journal of Environmental Studies, 27 (4), 1433, 2018.

15. SINGH R., BARMAN P.B, SHARMA D. Synthesis, structural and optical properties of $\mathrm{Ag}$ doped $\mathrm{ZnO}$ nanoparticles with enhanced photocatalytic properties by photodegradation of organic dyes. Journal of Materials Science, Journal of Materials Science: Materials in Electronics, 28, 5705, 2017.

16. PRADEEV R.K., SADAIYANDI K., KENNEDY A., SAGADEVAN S., CHOWDHURY Z.Z., JOHAN M.R.B., AZIZ F.A., RAFIQUE R.F., THAMIZ S.R., RATHINA B.R. Influence of $\mathrm{Mg}$ Doping on $\mathrm{ZnO}$ Nanoparticles for Enhanced Photocatalytic Evaluation and Antibacterial Analysis. Nanoscale Research Letters, 13 (1), 229, 2018.

17. HABBA Y.G., CAPOCHICHI-GNAMBODOE M., LEPRINE-WANG Y. Enhanced Photocatalytic Activity of Iron-Doped $\mathrm{ZnO}$ Nanowires for Water Purification. Applied Science, 7, 1185, 2017.

18. LAVAND A.B., MALGHE Y.S. Synthesis, characterization and visible light photocatalytic activity of carbon and iron modified ZnO. Journal of King Saud University - Science, 30, 65, 2018.

19. SUN S., CHANG X., LI X., LI Z. Synthesis of N-doped $\mathrm{ZnO}$ nanoparticles with improved photocatalytical activity. Ceramics International, 39 (5), 5197, 2013.

20. SUDRAJAT H., BABEL S. A novel visible light active $\mathrm{N}$-doped $\mathrm{ZnO}$ for photocatalyticdegradation of dyes. Journal of Water Process Engineering, 16, 309, 2017.

21. LAVAND A.B., MALGHE Y.S. Synthesis, characterization and visible light photocatalytic activity of nitrogendoped zinc oxide nanospheres, Journal of Asian Ceramic Societies, 3, 305, 2015.

22. VERMA N., YADAV S., MARI B., MITTAL A., JINDAL J. Synthesis and Charcterization of Coupled $\mathrm{ZnO} / \mathrm{SnO}_{2}$ Photocatalysts and Their Activity towards Degradation of Cibacron Red Dye. Transactions of the Indian Ceramic Society, 77 (1), 1, 2018.

23. CHANG Y-C. Complex $\mathrm{ZnO} / \mathrm{ZnS}$ nanocable and nanotube arrays with high performance photocatalytic activity. Journal of Alloys and Compounds, 664, 538, 2016.

24. DING M., YANG H., YAN T., WANG C., DENG W., ZHANG S., HUANG J., SHAO M., XU X. Fabrication of Hierarchical ZnO@NiO Core-Shell Heterostructures for Improved Photocatalytic Performance. Nanoscale Research Letters, 13, 260, 2018.

25. KUNDU P., DESPANDE P.A, MADRAS G., RAVISHANKAR N. Nanoscale $\mathrm{ZnO} / \mathrm{CdS}$ heterostructures with engineered interfaces for high photocatalytic activity under solar radiation. Journal of Materials Chemistry, 21, 4209, 2011.

26. REDDY C.V., BABU B., SHIM J. Synthesis, optical properties and efficient photocatalytic activity of $\mathrm{CdO} / \mathrm{ZnO}$ hybrid nanocomposite. Journal of Physics and Chemistry of Solids, 112, 20, 2018.

27. CHEN Q., HOU H., ZHANG D., Hu S., MIN T., LIU B., YANG C., PU W., HU J., YANG J. Enhanced visible-light driven photocatalytic activity of hybrid $\mathrm{ZnO} / \mathrm{g}-\mathrm{C}_{3} \mathrm{~N}_{4}$ by high performance ball milling. Journal of Photochemistry and Photobiology A: Chemistry, 350, 1, 2018.
28. YUAN X., ZHOU C., JIANG Q., TANG Q., MU Y., DU A. Facile Synthesis of $\mathrm{g}_{-} \mathrm{C}_{3} \mathrm{~N}_{4}$ Nanosheets/ZnO Nanocomposites with Enhanced Photocatalytic Activity in Reduction of Aqueous Chromium (VI) under Visible Light. Nanomaterials, 6 (9), 173, 2016.

29. LIU C., LI C., FU X., RAZIQ F., QU Y., JING L. Synthesis of silicate-bridged $\mathrm{ZnO} / \mathrm{g}-\mathrm{C}_{3} \mathrm{~N}_{4}$ nanocomposites as efficient photocatalysts and its mechanism. RSC Advances, 5, 37275, 2015.

30. LIU P., GUO Y., XU Q., WANG F., LI Y., SHAO K. Enhanced photocatalytic performance of $\mathrm{ZnO} /$ multi-walled carbon nanotube nanocomposites for dye degradation. Ceramics International, 40, 5629, 2014.

31. MU J., SHAO C., GUO Z., ZHANG Z., ZHANG M., ZHANG P., CHEN B., LIU Y. High Photocatalytic Activity of ZnO-Carbon Nanofiber Heteroarchitectures. ACS Applied Materials \& Interfaces, 3, 590, 2011.

32. ZHANG K., OH W-C. Effect of Heat-Treated Temperature on Surface Crystal Structure and Catalytic Activity of $\mathrm{ACF} / \mathrm{ZnO}$ Composite under Ultraviolet Irradiation and Ultrasonication. Journal of Korean Ceramic Society, 47 (2), 136, 2010.

33. LI Y., ZHANG B.-P., ZHAO J.-X., GE Z.-H., ZHAO X.$\mathrm{K}$., $\mathrm{ZOU} \mathrm{L}$. $\mathrm{ZnO} /$ carbon quantum dots heterostructure with enhanced photocatalytic properties. Applied Surface Science, 279, 367, 2013.

34. FENG C., DENG X-Y., Ni X-X., Li W-B. Fabrication of Carbon Dots Modified Porous $\mathrm{ZnO}$ Nanorods with Enhanced Photocatalytic Activity. Acta Physico Chimica Sinica, 31 (12), 2349, 2015.

35. BOZETINE H., WANG Q., BARRAS A., LI M., HADJERSI T., SZUNERITS S., BOUKHERROUB R. Green Chemistry Approach for the Synthesis Of $\mathrm{ZnO}$ Carbon Dots Nanocomposites With Good Photocatalytic Properties Under Visible Light. Journal of Colloid and Interface Science, 465, 286, 2015.

36. YU H., ZHANG H., HUANG H., LIU Y., LI H., MINGA H., KANG Z. ZnO/carbon quantum dots nanocomposites: one-step fabrication and superior photocatalytic ability for toxic gas degradation under visible light at room temperature. New Journal of Chemistry, 36, 1031, 2012.

37. ZHANG Z., ZHENG T., LI X., XU J., ZENG H. Progress of Carbon Quantum Dots in Photocatalysis Applications. Particle and Particle Systems Characterization, 33 (8), 457, 2016.

38. YANG P., ZHAO J., WANG J., CUI H., LIA L., ZHU Z. Pure carbon nanodots for excellent photocatalytic hydrogen generation. RSC Advances, 5, 21332, 2015.

39. LI H, LIU R., LIAN S., LIU Y., HUANG H., KANG Z. Near-infrared light controlled photocatalytic activity of carbon quantum dots for highly selective oxidation reaction. Nanoscale, 5, 3289, 2013.

40. CHU K-W., LEE S.L., CHANG C-J., LIU L. Recent Progress of Carbon Dot Precursors and Photocatalysis Applications. Polymers, 11, 689, 2019.

41. WANG H-X., XIAO J., YANG Z., TANG H., ZHU Z-T., ZHAO M., LIU Y., ZANG C., ZHANG H-L. Rational design of nitrogen and sulfur co-doped carbon dots for efficient photoelectrical conversion applications. Journal of Material Chemistry A, 3, 11287, 2015

42. LI B.J., CAO H.Q. ZnO@graphene composite with enhanced performance for the removal of dye from water. Journal of Materials Chemistry, 21, 3346, 2011. 
